\title{
GEOGRAFIA DO HIV/AIDS ENTRE FALAS: ANÁLISE DO DISCURSO DE JOVENS SOROPOSITIVOS EM PRESIDENTE PRUDENTE, SP
}

\section{GEOGRAPHY OF HIV / AIDS AMONG SPOKES: ANALYSIS OF THE SPEECH OF YOUNG SOROPOSITIVES IN PRESIDENTE PRUDENTE, SP}

\author{
Mateus Fachin Pedroso \\ Mestrando em Geografia da FCT/UNESP - Presidente Prudente \\ mateus fachin@hotmail.com \\ Raul Borges Guimarães \\ Professor Titular do Departamento de Geografia FCT/UNESP - Presidente Prudente \\ raul@fct.unesp.br
}

\begin{abstract}
RESUMO
O recrudescimento da AIDS e o surgimento de novos casos de HIV na população jovem brasileira é um tema de grande relevância para a Geografia da Saúde na atualidade. Esta problemática permitiu-nos trazer a discussão para nosso recorte espacial, que expressa o recrudescimento de novos casos de HIV/AIDS na população jovem em Presidente Prudente - SP. A partir dos contextos geográficos dos jovens, teve-se como principal objetivo compreender os modos que os jovens vivenciam os processos de adoecimento a partir da análise dos discursos, e apontar quais são os impactos e ressignificações que ocorrem em suas práticas cotidianas. Este trabalho foi realizado nos anos de 2015, 2016 e 2017, através de trabalhos de campo e análises pautados em metodologias qualitativas, que possibilitaram a interação com jovens e seus contextos geográficos. Desta forma, foi possível identificar os impactos causados pelo diagnóstico do HIV/AIDS em suas vidas, as dificuldades e ressignificações espaciais decorrentes deste processo de transformação, ao ponto que também emergiram fatores atinentes a saúde destes jovens, que vão desde problemas referentes à adesão ao tratamento, manutenção e qualidade de vida até a cogitação de suicídio, o que expressa elevado grau de complexidade.
\end{abstract}

Palavras-chave: Geografia da Saúde. HIV/AIDS. Jovens. Análise do discurso. Pesquisa qualitativa.

\begin{abstract}
The recurrence of AIDS and the emergence of new HIV cases in the Brazilian young population is a subject of great relevance for Health Geography today. This problem allowed us to bring the discussion to our spatial clipping, which expresses the upsurge of new cases of HIV / AIDS in the young population in Presidente Prudente - SP. From the geographic contexts of young people, the main objective was to understand the ways in which young people experience the processes of illness from the analysis of discourses, and to point out the impacts and re-significances that occur in their daily practices. This work was carried out in the years 2015, 2016 and 2017, through fieldwork and analyzes based on qualitative methodologies, which enabled the interaction with young people and their geographical contexts. In this way, it was possible to identify the impacts caused by the diagnosis of HIV / AIDS in their lives, the difficulties and spatialization resulting from this process of transformation, to the point that factors related to the health of these young people also emerged, ranging from problems related to adherence to treatment, maintenance and quality of life until suicide, which expresses a high degree of complexity.
\end{abstract}

Key words: Geography of Health. HIV / AIDS. Young. Speech analysis. Qualitative research.

Recebido em: 06/02/2019

Aceito para publicação em: 01/04/2019 


\section{INTRODUÇÃO}

Atualmente, temos ${ }^{2}$ vivenciado em escala nacional o recrudescimento do HIV/AIDS em diversos seguimentos da população brasileira. Hoje, considera-se a população jovem como umas das mais afetadas, dado ao surgimento de novos casos de HIV/AIDS ${ }^{3}$ no Brasil (BRASIL, 2014). Segundo o mais recente Boletim Epidemiológico-HIV/AIDS, é de destaque o aumento da taxa de detecção de AIDS (x100 mil habitantes) em jovens de 15 a 29 anos alcançando "[...] a maior taxa de detecção em 2017 de 50,9 casos/100.000 habitantes, que ocorreu entre os indivíduos na faixa etária de 25 a 29 anos, tendo superado as taxas de detecção em homens de 30 a 34 anos e de 35 a 39 anos, que eram mais prevalentes até o ano de 2016" (BRASIL, 2018, p. 15). Tais dados apontam o contexto geral do Brasil, e expressam uma significativa reorganização das camadas que têm sido acometidas pela doença, demandando assim, respostas adequadas das políticas públicas de saúde voltadas à essa população.

Frente a esta configuração, entendemos que o recrudescimento da AIDS e o surgimento de novos casos de HIV na população jovem brasileira é um tema que precisa de maior atenção dos grupos de pesquisa e das universidades, que carece de debate e aprofundamento em todas as áreas, em nosso caso no campo da Geografia da Saúde. Afinal, se a doença tem grande relevância para a saúde pública, entende-se que a ciência geográfica tem profundos lastros com a organização dos espaços e suas políticas que se regionalizam e territorializam, podendo contribuir para a análise do contexto espacial no qual a doença é produzida (BARCELLOS; BASTOS 1996; GUIMARÃES, 2008).

Para isto, é preciso considerar os diversos trabalhos produzidos na Geografia, Ciências médicas, Saúde Coletiva sobre o tema, seja em escala nacional, estadual ou local, assim como diversas abordagens que visam uma melhor compreensão geográfica do fenômeno do HIV/AIDS no Brasil (COSTA-COUTO, 2007, SILVA, 2003; PRADO, 2008; BUENO, 2010; ALVES, 2010; MARCHETTI, 2011; OLIVEIRA, 2011).

Isso faz com que pensemos nos diferentes contextos geográficos vivenciados por estas pessoas, em nosso caso os jovens, levando em consideração a tramitação do processo de adolescer com a presença do HIV/AIDS, o que é uma situação extremamente complexa (LIMA; PEDRO, 2008). Partindo deste pressuposto, se mostra necessário discorrer sobre como isso repercute não somente em questões numéricas, mas também, na perspectiva do sujeito, para que se tenha uma visão abrangente do processo de adolescer com HIV/AIDS (CORVINO, 2012; PEDROSO, 2017).

Tendo estes pressupostos como preocupação, buscamos pelo entendimento do contexto dos jovens, relacionando com o recrudescimento do HIV/AIDS no município de Presidente Prudente - SP. Para isto, se fez necessário um aprofundamento sobre esta temática, visto que são amplos os debates que existem acerca das juventudes, bem como do que é concebido por saúde dos jovens.

Desta forma, a apreensão da realidade se dá através dos contextos geográficos vivenciados no dia-adia, o que pode ser compreendido através das falas, das enunciações, dos discursos dos sujeitos. Tomando esse princípio como norteador, realizamos entrevistas com jovens soropositivos HIV/AIDS residentes em Presidente Prudente - SP, para que pudéssemos compreender seus contextos de vida e as percepções que estes têm sobre si e sobre o seu entorno, com o objetivo de elucidar de que modo os jovens vivenciam os processos de adoecimento a partir da análise dos discursos, e apontar quais são os impactos e ressignificações que ocorrem em suas práticas cotidianas (CERTEAU, 2008).

\footnotetext{
2 Apesar de ainda predominar uma visão conservadora de que os artigos científicos devam assumir a impessoalidade no tratamento da conjugação verbal enquanto "visão hegemônica", optamos pela adequação que parte de necessidades reais, estando estas embasadas nas contribuições de Oliveira (2014). Adotamos no presente artigo o emprego da primeira pessoa do plural, pois é consenso que "[...] a despersonalização do discurso provoca um distanciamento do autor e deixa na penumbra seu próprio compromisso com o resultado. $\mathrm{O}$ texto, hoje, prevê uma interlocução autor-leitor; o autor cobra um envolvimento direto do leitor com o seu pensamento, o seu raciocínio. O leitor é trazido para dentro do texto, é partícipe desse texto" (OLIVEIRA, 2014, p. 10). Em consonância à isso cabe ressaltar que a posição assumida por nós está diretamente conectada com a metodologia empregada no realizar da pesquisa.

3 O Human Immunodeficiency Vírus (HIV) é o vírus que ataque às células linfócitos TCD4+ do sistema imunológico humano, e em casos de infecção extrema tornando o sistema vulnerável e susceptível ao surgimento da Acquired Immunodeficiency Syndrome (AIDS) (BRASIL, 2014).
} 


\section{METODOLOGIA}

Partindo destas premissas, foram realizadas as entrevistas com os jovens soropositivos através da aproximação com a Associação Prudentina de Prevenção a AIDS (APPA) ${ }^{4}$, uma vez que a coordenação da associação apresentava a pesquisa e seus objetivos aos sujeitos jovens frequentadores da ONG, cabendo aos jovens decidirem participar ou não das etapas da pesquisa, fazendo com que as entrevistas fossem realizadas por conveniência.

Este trabalho foi realizado nos anos de 2015, 2016 e 2017, através de trabalhos de campo (ZUSMAN, 2011) pautados em metodologias qualitativas, que possibilitaram a interação com jovens que se mostravam em situação de vulnerabilidade (PEDROSO; GUIMARÃES, 2015, PEDROSO, 2016). Decorrente desta aproximação, foram realizadas entrevistas com 4 sujeitos que se mostraram dispostos a compartilhar suas histórias e vivências, para que assim pudéssemos interpretar os contextos geográficos vivenciados.

As entrevistas aconteceram subsidiadas pela disposição dos sujeitos, ao ponto que foram realizadas de forma individual, tendo como instrumento metodológico de pesquisa o roteiro semiestruturado (MANZINI, 1991, 2004), que serviu de base para a produção das informações acerca dos contextos dos jovens. As perguntas que compunham o roteiro foram organizadas em campos temáticos que buscavam pelas interseccionalidades dos sujeitos entrevistados, ressaltando que os temas abordados foram: HIV/AIDS, Saúde, Trabalho/Escola/Faculdade, Corpo, Militância, Lazer, entre outros que se fizeram necessários para a construção do entendimento da proposta.

Cabe também destacar enquanto passo metodológico que as entrevistas foram gravadas (áudio) com a autorização dos participantes, estando estes princípios regidos pelo Sistema Nacional de Ética em Pesquisa e aprovados pelo Comitê de Ética em Pesquisa da Faculdade de Ciências e Tecnologia UNESP ${ }^{5}$. Enquanto etapa conseguinte, realizou-se a transcrição das entrevistas, para que assim fosse viável a realização das interpretações. Destacamos neste ponto, a preocupação com a fidelidade do que se foi dito nas entrevistas, de modo que estas foram transcritas de forma literal (MANZINI, 2010). Realizado isto, partimos para a constituição das primeiras análises qualitativas dos dados textuais realizadas com o suporte do software ATLAS/ti, que permitiu a integração e visualização destes dados para uma exploração primária (PÁRAMO, 2010).

Por meio deste recurso, trabalhamos os dados qualitativos sob a perspectiva aplicadas à saúde, sendo assim, possível a sistematização dos resultados, visto que o software potencializa o estabelecimento de relações presentes nas falas no processo de análise do discurso de forma conjunta (PEDROSO, 2017). Evidentemente, que o ALTAS/ti é tido como uma ferramenta muito útil nas análises, no entanto, não realiza os cruzamentos e interações de forma finalizada, pelo fato de que as interpretações das falas vão além dos processos mecânicos realizadas pelo suporte tecnológico.

Para isso é preciso centralizar esforços na identificação das evocações presentes nas falas dos sujeitos; evocações estas que fazem menção às espacialidades que os sujeitos vivenciam e produzem (ORNAT, 2008), pois, acreditamos ser possível a compreensão do contexto geográfico que os sujeitos estão inseridos, buscando pelas evocações implícitas nos relatos orais, ou seja buscando pelas espacialidades discursivas. Para isto, foi necessário o desenvolvimento de uma abordagem que buscasse a fundo o sentido léxico nas evocações presentes nas entrevistas, visto que, "a análise fora de contexto efetivamente se constitui apenas como o primeiro acesso para uma abordagem; num segundo nível consideraria os enunciados em contexto para descobrir a diversidade dos processos argumentativos [...]" (MAINGUENEAU, 1997, p. 138).

Assim, os dados foram preparados para o primeiro tratamento, por meio da realização da codificação, na qual foram buscadas as palavras-chaves compreendidas como elementos nevrálgicos das

\footnotetext{
${ }^{4}$ Associação Prudentina de Prevenção a AIDS (APPA) é uma Ong - DST/AIDS fundada em 28 de setembro de 1992, presta atendimento social, psicológico, preventivo a todos aqueles que possuem o vírus HIV/AIDS, que são encaminhados pelos órgãos públicos da Saúde e não possuem condições financeiras de prover seu próprio sustento, sem distinção de idade, nacionalidade, cor, sexo ou religião. Paralelamente se trabalha a prevenção através de palestras informativas, educando e orientando à comunidade em geral nos locais de trabalho, sendo em indústrias, escolas, outras ONG's, etc., com o intuito de sensibilizar e conscientizar a importância real da doença, além de amenizar a discriminação e subsequentemente o preconceito.

${ }^{5}$ As entrevistas realizadas foram aprovadas para a realização e desenvolvimento da pesquisa e estão sob resguardo do CAAE (Certificado de Apresentação para Apreciação Ética): 46879615.0.0000.5402. DOI:http://dx.doi.org/DOI 10.14393/Hygeia153146917 Hygeia 15 (31): 82 - 94, Março/2019 página 84
} 
evocações encontradas, visto que estas são definidas "[...] através de uma grade explícita de análise de vocabulário que leva em conta, a um só tempo, o funcionamento da formação discursiva e o valor da unidade em língua" (MAINGUENEAU, 1997, p. 151). É a partir das palavras-chaves que podemos compreender a rede que se está por detrás das evocações consubstanciadas, de forma que se faz viável a identificação que as aglutinam por suas características e semelhanças. Deste modo, torna-se possível à compreensão da interação do individual para com o coletivo, elucidando assim, a conformação do contexto geográfico dos jovens soropositivos.

Enquanto sequência, desdobraram-se as etapas seguintes, que realizaram as conexões e relações entre os códigos elaborados a partir da fala dos sujeitos. Essas relações são permeadas por anotações visando, assim, o aprofundamento da codificação no decorrer do processo. Sendo assim, tomamos como embasamento a teoria fundamentada desenvolvida por Strauss e Corbin (2008), denominada de microanálise, que consiste na lapidação e polimento dos dados para que haja um olhar diferenciado sobre o fenômeno que ocorre, possibilitando assim, uma melhor compreensão da situação, proporcionando a viabilização de ligações mais intensas entre as palavras-chaves e seus significados sintagmáticos.

Deste modo, pautamo-nos em específico na análise do discurso (MAINGUENEAU, 1997) pelo fato desta metodologia permitir uma análise minuciosa e profunda, que possibilita a imersão no contexto de vulnerabilidades frente ao HIV/AIDS vivenciado por estes jovens. Com este caminho almejamos evidenciar de forma clara as "consequências que a camada jovem vem sofrendo com o acometimento desta doença, visto que esta se mostra cada vez mais agressiva, transformando assim, o cotidiano destes jovens" (PEDROSO, 2017).

Esta análise de conjunto considera as análises individuais e reforça a compreensão destes jovens enquanto um grupo de sujeitos, considerado por nós como o contexto jovem de Presidente Prudente frente ao HIV/AIDS. Em decorrência disso, torna-se de suma importância considerar as vivências destes sujeitos na produção dos contextos geográficos (PESSOA; RAMIRES, 2013), vislumbrando os impactos que foram causados nas práticas espaciais dos sujeitos frente ao diagnóstico de HIV/AIDS.

\section{RESULTADOS E DISCUSSÕES}

Ao pensarmos na vida das pessoas, especificamente dos jovens que habitam e produzem a cidade, intrinsecamente, problematizamos a respeito da saúde coletiva. Afinal, falamos sobre o acesso e o uso dos serviços, assim como a saúde físico-biológica e social, que garantem as condições mínimas para os jovens viverem a saúde em sua plenitude. Afinal, esses sujeitos "[...] são sujeitos sociais que, como tais, constroem um modo de ser jovem, ou seja, constroem a sua condição juvenil de acordo com os espaços, tempos e contextos em que vivem" (PAULA; PIRES, 2013, p. 89).

Sabemos que ainda nos dias atuais é muito árduo colocar-se a pensar o quem vem a ser ou mesmo deveria ser conceituado como saúde, visto que, é de extremo reducionismo determinar saúde como a ausência de doença, ou simples nexo causal direto (CANGUILHEM, 1990; CZERESNIA, 2003; BASTOS, 2011). Pelo contrário, é preciso reconhecer a saúde coletiva como uma construção social, um bem humano, com diversos sentidos (STOTZ, ARAUJO, 2004, p. 6). E essa construção social nos possibilita compreender as formas de vida, de trabalho, o lazer, a escola e a própria cidade como fontes de saúde, que constituem-se em recursos para a criação de uma sociedade saudável, sendo apontadas como prioridade estratégica no desenvolvimento de ambientes que facilitem e favoreçam a saúde (VERDI, CAPONI, 2005, p.85).

Com este intuito, leva-se em consideração a perspectiva e a voz dos sujeitos para a construção das propostas de organização dos serviços de saúde voltados aos PVHA. Assim, entendemos que é necessário o fortalecimento de laços entre o sistema de saúde e os sujeitos que usufruem deste, de modo que esta relação se torne mais humana e acessível à aqueles que necessitam.

Neste momento, se faz necessário o entendimento dos processos de saúde e doença (ALMEIDA FILHO, 2011) visto que para compreendê-los melhor "é preciso abordar a experiência da doença como processo subjetivo e buscar entender o mundo do sofredor" (LANGDON, MALUF, TORNQUIST, 2008, p. 128) de forma que seja possível uma ampliação na visão que se refere às políticas públicas de saúde e seu modo de organização, pois, para pensá-las devemos considerar "questões como o acesso universal, a equidade, a humanização e o respeito à cultura e ao conhecimento do outro, [...] uma vez que é um problema coletivo e social [...]" (LANGDON, MALUF, TORNQUIST, 2008, p. 128). 
Assim, muitas destas propostas e provocações se fazem urgentes e carecem de aprofundamentos, visto que foram constatados elementos importantes nos discursos enunciados, estando relacionados ao processo de adoecimento, os serviços de saúde e a subjetivação social dos sujeitos, como apresenta a figura 01 .

Figura 01 - Grafo discursivo - Espaços: saúde e doença

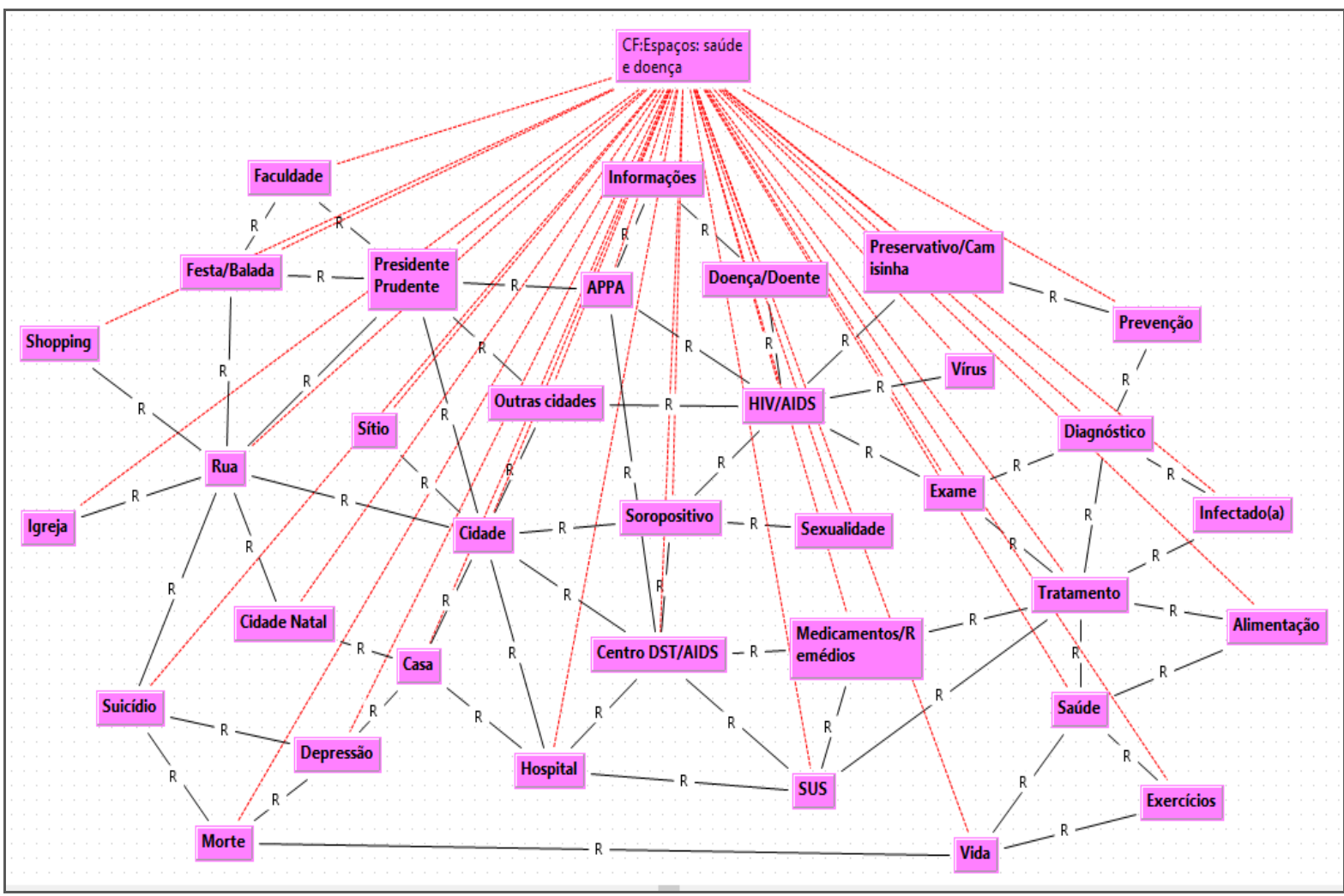

Fonte: PEDROSO, 2017 (p. 77)

O que é respectivo ao campo "Saúde-doença", destaca-se em primeiro momento a quantidade de palavras-chaves relevantes para com o contexto geográfico dos jovens entrevistados. Dentre estas, destacam-se palavras que vão desde os cuidados relacionados ao ideário de saúde como: 'Alimentação', 'Exame', 'Diagnóstico', 'Informações' e 'Prevenção', bem como palavras que estão ligadas diretamente a concepção de doença ('HIVIAIDS', 'Suicídio' e 'Vírus').

Assim, destacam-se algumas palavras no que se refere as interlocuções enunciativas, como é o exemplo da palavra-chave 'Diagnóstico', que emerge principalmente no momento em que os jovens realizam os exames de testagem, bem como apresenta-se nas falas sobre os impactos decorrentes do 'Diagnóstico' para si e para o entorno. Outra palavra relevante que é apresentada nos relatos é a "Morte" que se apresenta sobre a perspectiva que o sujeito passa a ter de si em relação à continuidade da vida frente ao medo relacionado à 'Morte', tendo assim, estritas relações com as vivências do luto (SOUZA, 2008). A última palavra, mas não menos importantes, que expressa elevada significância dentro deste campo é o 'Tratamento' que estabelece ligação com as anteriores, visto que é a etapa posterior ao 'Diagnóstico', como também vem a ser de suma importância para a manutenção e qualidade de vida dos sujeitos a longo prazo, evitando as diferentes doenças e a possibilidade de 'Morte' relacionada ao HIVIAIDS. Desta forma, fica exposta esta primeira análise em relação às palavras-chaves enunciadas presentes nas evocações das entrevistas realizadas. Esta análise primária vai no sentido de aproximar os pontos semelhantes que há entre os entrevistados, de modo, que elucidam características que compõem o contexto geográfico dos jovens soropositivos prudentinos. 
No segundo nível de análise, realizamos a interpelação destas categorias primárias, desempenhando uma interpretação profunda dos dados qualitativos, que passaram a conectar campos específicos que fazem menção ao contexto geográfico destes jovens. Levando em consideração os preceitos que foram destacados anteriormente, construiu-se o grafo 'Espaços: Saúde e doença', que abarca os elementos destacados pelos quatro entrevistados no que se refere às suas interpretações sobre saúde e doença. Analisando o grafo, podemos notar com destaque as centralidades presentes realizadas por algumas palavras-chaves enunciadas, que se mostraram com maior peso e poder de articulação, expressando a capacidade de ligação entre as diferentes partes da rede discursiva.

Dentre as inúmeras centralidades apresentadas, destaca-se a 'Cidade' que neste campo temático tem a função de articulação dos demais espaços presentes que constituem as vivências dos entrevistados. É na 'Cidade' que as ações se desempenham e a partir de tais se concebem as interpretações de saúde e doença. A 'Cidade' estabelece ligações diretas com a 'Casa' dos sujeitos, visto que esta é interpretada como um mundo dentro de outro mundo, de forma que, a 'Casa' também tenha importante papel no que se refere ao processo saúde-doença dos indivíduos.

Neste sentido, faz-se importante a compreensão da questão da escala, já que esta é a medida que confere visibilidade aos fenômenos socialmente construídos (MARSTON, 2000). Neste sentido, ancoramo-nos em Castro (2007) que reforça que a escala "não define, portanto, o nível de análise, nem pode ser confundida com ele, estas são noções independentes conceitual e empiricamente" (CASTRO, 2007, p. 123). Tais concepções tornam-se relevantes quando refletimos sobre as diferentes escalas presentes nos contextos geográficos dos sujeitos, uma vez que estas se interpelam mutuamente, o que nos faz perceber os fenômenos sob uma visão transescalar.

Tais colocações se evidenciam no decorrer dos estudos e das análises, já que compreendemos que a 'Casa' é ressignificada e passa a ser o único espaço que os jovens produzem e vivenciam. Isso implica na vida dos sujeitos em diversos segmentos, desde a alteração de suas práticas espaciais até os desdobramentos referentes à saúde e a possibilidade do adoecimento em decorrência desta reclusão, como pode ser exemplificado pelo estágio desânimo e tristeza, materializados na insurgência da 'Depressão', como é evidenciado no relato de 'E':

[...] já tava de saco cheio, não gostava mais da cidade. Chegou no limite sabe?! Aí entrei em depressão... depressão, entrei em depressão, vendi todas as coisas que eu tinha na minha casa, tudo, fui embora (Sujeito E).

$\mathrm{Na}$ fala do sujeito podemos notar alguns dos impactos que se é apresentado em decorrência do descontentamento e da 'Depressão', e é por estas vias que entendemos a ocorrência de distintas mudanças nas vidas dos sujeitos, que alteram suas percepções e práticas, e consequentemente repercutem em sua saúde psicológica e social. É neste interstício que se menciona a possibilidade do 'Suicídio' evocado enquanto consequência do estágio agudo de depressão. Nunes et al. (2005) nos alerta que estes fatores já são agravados dado que, "a depressão maior na adolescência é comum, debilitante, e recorrente, envolvendo um alto grau de morbidade e mortalidade e um dos maiores problemas de saúde pública, embora não diagnosticada e não tratada" (NUNES, et al., 2005, P. 111).

Sob estas prerrogativas, ao indagarmos sobre a sua saúde alguns entrevistados apresentaram suas percepções acerca da 'Depressão' e dos elementos psicossociais, como evidenciam os trechos relatados por 'E':

[silêncio antes de iniciar a resposta] De regular pra ruim, de regular pra ruim, porque varia muito do dia sabe, tem dias que eu não to legal, e ai bate uma depressão, pensamentos que nossa senhora, tem que rezar muito sabe pra sair da mente, então como eu acho que o fator psicológico é de extrema importância isso machuca muito, muito, muito, muito (Sujeito E).

Ai começou aquela questão assim, ai vou me matar e acabar com tudo isso né, você pensa desse modo, ai falei poxa, se eu contar pra minha mãe que eu sou soropositivo já vai matar ela, imagina se eu me matar, ai que vai matar a família inteira né, piora ainda a situação (Sujeito E).

A partir das dos discursos evidencia-se a vulnerabilidade em que o sujeito se encontra em relação à situação atual de sua saúde, criando a partir de sua instabilidade a possibilidade de atentar contra a própria vida. Estes fatores voltados à saúde, em relação à 'Vida' e a 'Morte' (BASTOS, 2006) estão arraigados por questões que pertencem ao convívio social, pelo fato de que, os adolescentes e adultos jovens estão em uma fase chave de socialização em termos de carreira profissional e 
relações interpessoais, esse índice indica um considerável risco potencial para complicação e futuro risco de cronicidade do estado de depressão (NUNES, et al., 2005, P. 111).

Vê-se que é uma luta constante do sujeito com ele próprio, de forma que, de um lado se tem a possibilidade da 'Morte' e a "eliminação do problema", e de outro a continuidade da 'Vida' com novos valores agregados: o convívio com o HIV. Esses valores têm uma estrita relação com a interação dos processos de vivência do luto do sujeito (SOUZA, 2008), o que leva a lidar com a situação de forma subjetiva e pessoal, quando se trata dos processos de saúde e doença. Nota-se que a pulsão de morte está presente no cotidiano destes jovens, de forma acentuada, principalmente, nos momentos iniciais como a confirmação da sorologia positiva, como relata ' $T$ ' e 'E':

Tipo, eu pensei em me matar, ai depois [...] ainda bem que ficou só dois dias esse pensamento na cabeça, mais aí depois eu falei: „Pô a vida é tão longa, se eu fiz por onde então eu não tenho que reclamar, não tenho que fazer dum copo d'água um redemoinho (Sujeito $\mathrm{T}$ )

Já, já tentei já, eu já me automediquei com uns trinta comprimidos já, ai eu dormi umas 72 horas seguidas mais ou menos, entendeu?! E penso ainda, penso, ainda vem. Vô falar pra você que vem esse tipo de pensamento cabeça. Vem e ele é constante, é uma constante, é só ficar em casa pra uns dois, três dias que o pensamento vem, pensamento vem (Sujeito E).

O estágio de depressão e a forma com a qual se lida com esta problemática, estão atrelados à conformidade que os sujeitos assimilam a esta nova situação e se posicionam frente à nova realidade. Deste modo, entendemos que o processo de reclusão rompe os vínculos sociais desempenhados pelos sujeitos, visto que, a limitação dos indivíduos ao espaço da 'Casa' é não raramente prejudicial a 'Saúde' mas também a 'Vida' dos sujeitos. Assim, fica visível que a 'Casa' estabelece diferentes relações no que se refere aos espaços e a saúde e doença, de modo, que está interligada com a 'Cidade' e com os demais espaços que produzem as interpretações de saúde e de doença dos sujeitos, bem como o 'Hospital'.

A evocação da espacialidade discursiva 'Hospital' na vida dos sujeitos tem um papel referente à ação curativa imediata, transparecendo e fixando um ideal de modelo hospitalocêntrico e medicalizador, que faz com que os indivíduos na maioria das vezes concebam saúde como ausência de doença, ou mesmo, a cura para tais, como se expressa ' $\mathrm{J}$ ':

Ai maínha foi e me levou pro hospital pra eu saber porque eu tinha isso, assim... ai eu fui pro hospital, ai chegou lá tive de começar o tratamento de novo e tal, sendo que eu nem tinha feito tratamento, não podia tomar a medicação, não podia (Sujeito J).

Além disso, o 'Hospital' também tem um papel de peso no que se direciona a vida e aos cuidados da saúde, visto que estabelece ligação direta com o 'Tratamento' como expressa 'l' ao falar sobre sua trajetória e experiência dado que convive com o vírus desde seu nascimento:

Hoje eu vejo que melhorou bastante, porque quando eu era pequena, é, tipo assim, eu inchava aqui no pé do ouvido [mostrou com a mão o lado direito do rosto] tipo, tinha que tomar bastante antibiótico [...] antibiótico pra parar de inchar, duía (doía) bastante, bastante [ênfase ao falar da dor] e agora normal, não incha mais (Sujeito I).

O tratamento em si não é somente ao que se refere ao uso dos 'Medicamentos', mas sim a todo o tipo de assistência que é desempenhado para com o sujeito, assegurando que suas necessidades dos sujeitos sejam atendida em todas as esferas, desde o momento da descoberta do 'Vírus' até o início do uso da medicação. É de suma importância ter-se uma visão holística no que se refere ao 'Tratamento', pois, desta forma, compreende-se melhor a situação do sujeito no que tange ao enfrentamento e aceitação desta nova situação, com nos explícita 'J':

É... mais ou menos, eu fiquei... tô tranquila, tô pensando agora em... tô tomando a medicação certinho, agora é bola pra frente né?!, agora que vacilou é olhar pra frente, tentar conviver com isso né?! tentando viver né?! até agora tem dado certo. Sei que vai ser pro resto da minha vida, mas [frase reticente] (Sujeito J).

O 'Tratamento' também implica o momento do diagnóstico e a forma com a qual esse foi dado, e como se passou a lidar com essa nova realidade frente ao tratamento pelos 'Medicamentos', uma vez que o cuidado com pessoas enfermas "conjuga o tratamento adequado pelo conhecimento e tecnologia médica a atenção aos aspectos ligados à abertura de novas possibilidades de vida. É necessário estimular a criação dos meios orgânicos e psíquicos para resistir as limitações imposta 
pela doença" (CZERESNIA, MACIEL, OVIEDO, 2013, p. 26). Assim entendemos que estas interfaces estão ligadas ao 'HIVIAIDS' como também são conexas aos seus desdobramentos, desde a fase do 'Exame', 'Diagnóstico' e a constatação de estar 'Infectado (a)', de forma que tais fases repercutiram em mudanças na vida dos jovens.

Essas abruptas transformações estão interligadas com as adaptações e readequações que os sujeitos tendem a se equalizar, em grande maioria ligadas ao início do 'Tratamento', aproximando-os dos 'Medicamentos/Remédios', sendo esta uma parte difícil para os sujeitos, tanto pela questão da habitualidade com esta nova rotina, como também da adaptação com as reações decorrentes da medicação, como se é enfatizado pelos entrevistados 'E' e 'T':

Tô com os medicamentos em casa, até então fiquei uma semana sem tomar depois que eu peguei porque eu não tinha coragem, era como se eu olhasse pra aquele medicamento e uma ferida em mim se abrisse internamente, entendeu?! [...] Tem as reações do medicamento também, ontem mesmo eu tomei o medicamento e ficou parecendo que eu tinha tomado uns 5 litros de cachaça mais ou menos, eu não conseguia me manter em pé entendeu?!". (Sujeito E).

Aí, ele (médico) me passou uns remédios, um só, e aí eu tomei, e aí eu fiquei mal pra cacete até me adaptar. [...] Tipo me sentia muito mal, muito mal (Sujeito T).

Frente a estas situações é natural que se busque por apoio e respaldo em relação à nova condição enfrentada pelos jovens, e, é no espaço da 'APPA' que estes jovens se identificam e recebem os devidos acolhimentos. Para eles, a 'APPA' é um ponto de interface para a interpretação enquanto aprendizagem ao se lidar com o 'HIVIAIDS', ao mesmo tempo em que se é aprendido 'Informações' que contemplam esta nova realidade, como é expresso no relato de ' $E$ ':

$\mathrm{Ai}$, enfim, comecei o tratamento, ai a socióloga falou pra mim desse espaço, eu ainda tive uma resistência pra descer até aqui, no dia que eu desci eles estavam fazendo alguma coisa aqui dentro ai eu falei assim ai não sei se eu vou ficar, ai a menina da recepção começou a falar, falar, falar, fui ficando entendeu?! (Sujeito E).

O relato do sujeito em questão evidencia o que foi citado anteriormente, de forma que além de se compor um ambiente que proporcione tais subsídios, também vem a ser um espaço de identificação e acolhimento para os jovens que estão em situação de vulnerabilidade. Tais elementos são confirmados também, por ' $T$ ' quando indagado sobre os trabalhos de entidades como a 'APPA' e a relevância e importância que estas têm para com os que necessitam deste tipo de serviço; segue o trecho relatado:

Legal, legal, porque se não fosse isso eu acho que não estaria hoje no rádio, na TV, na maioria das vezes fala. Acho que seria uma coisa mais escondida, uma coisa mais privada, as pessoas não iam ter tanto recurso e ficar: "Ah tipo, pô, tá saindo tal remédio pra isso, muitas vezes essas entidades passa esse tipo de informação (Sujeito T).

Todos estes fatores estão diretamente ligados ao 'HIVIAIDS', que na rede de relações estabelece papel de centralidade englobando uma série de facetas relacionais, desde a manifestação da 'Doença' em decorrência da presença do 'Vírus' até as formas de 'Prevenção' (MONTEIRO, 2002). As percepções sobre saúde e principalmente sobre a doença, pautadas em questão são diferentes, de modo que os jovens entrevistados a enxergam de maneira peculiar e particular a sua realidade, visto que a interpretação de doença está arraigada ao contexto em que se vive e ao tempo em que se está situada, como evidencia as falas dos entrevistados 'E' e 'l':

Meu posicionamento sobre o HIV/AIDS (momento de silêncio e reflexão). É algo mortal ainda, por mais que se tenha tratamento entendeu?! Mas as pessoas hoje em dia tem que ter a ciência e a consciência de que tratamento não é cura, entendeu?! $\mathrm{E}$ que, as pessoas hoje em dia dizem aí hoje ninguém mais morre de HIV/AIDS. Você não vai morrer de AIDS/HIV, mas e as doenças oportunas? Entendeu?! Essas sim vão te matar, vão te matar com mais facilidade devido ao HIV/AIDS, entendeu?! (Sujeito E).

Eu tenho visto tipo, tem pessoas que se cuida, mas tem pessoas que não se cuida, então é tipo, as que se cuida você não vê aquelas manchas vermelhas, cheio de coceira, as tipo, é bem feia, agora aquelas que se [...] tipo que não se cuida... difícil (Sujeito I). 
Na fala de 'E' notamos a ênfase que se é dada à despreocupação com o 'HIVIAIDS' por parte dos jovens, visto que hoje a doença é interpretada com o tom de cronicidade (SCHAURICH; COELHO; MOTTA, 2006), que também é endossada pelo relato de 'l'. Concordamos que houveram progressos no que tange aos cuidados de saúde das PVHA, mas também apontamos que esse fator gerou certa despreocupação na população, principalmente na parcela jovem, que não presenciou a fase mais agressiva da AIDS no Brasil. Essa dualidade pode ser presenciada na fala de 'T' que apresenta a doença como uma 'gripe', no entanto, hoje reconhece os cuidados e precauções que tem que tomar perante a presença do HIV em sua vida:

Pô, eu acho que é igual eu falei, não é porque você tem uma "gripe" que você vai fazer dela uma doença gravíssima, vai se trancar dentro de um quarto e vai chorar e não vai comer. Não! Eu vou cuidar da gripe, vou sair no sol, vou ir pra praia. Eu vou... vou ir viver a minha vida. Eu sou novo, hoje já até tenho cabelo branco, mas eu quero viver muito! (Sujeito T).

Tratando-se dos cuidados que são necessários, é inevitável não se pensar em 'Prevenção' (MONTEIRO, 2002). Isso exige um grande esforço em inúmeros fatores que vem a compor a arte de combater a doença por meio da disseminação de informações, de forma, que este acontecimento não se desprende da Geografia, visto que, atualmente é cabível a Geografia da Saúde buscar por pontos de enfretamento das doenças a partir do que as originam, e não combatê-las exclusivamente através de atos curativo-medicalizador, de modo paliativo (ROJAS, 2003).

Quando se inicia a discussão sobre 'Prevenção' relacionada ao 'HIVIAIDS', logo emerge como pauta principal o uso do 'Preservativo/Camisinha', que é interpretado como o único ato de se evitar a transmissão do HIV/AIDS ou outras IST's, tal concepção é tida em maioria pelos jovens, mesmo que muitos destes ainda não façam o uso do 'Preservativo/Camisinha' como expressa o relato de 'E'.

[...] também poderia ter falado não opa, sem camisinha não rola, né, mas nessas horas a gente pira a cabeça esquece... quem nunca né?! (Sujeito $E$ ).

No entanto, nota-se a importância que é dada a esta questão, visto que em decorrência do prognóstico os jovens entrevistados passem a ter outras novas percepções relacionadas à 'Prevenção', ao uso do 'Preservativo/Camisinha' e à outros cuidados como como expressam as falas dos entrevistados ' $\mathrm{T}$ ' e J':

[...] já fiz muito programa, me montei de trava, e tipo eu não avisava, mas sem preservativo não dá! (Sujeito T).

Ai tem que se [...] usar preservativo, tem que se cuidar, pra evitar tudo isso. Ninguém quer estar com isso, ninguém quer, essa é a verdade. Mas tem de se prevenir, coisa que eu também não fiz (Sujeito J).

Destacada este campo que compõe a 'Prevenção', elucidamos o fato que esta não é somente a única via, visto que se promove a prevenção também, por meio da disseminação de informações, conscientização e políticas de base enfocadas nos sujeitos-alvo de interesse. Muito nos chamou a atenção uma das falas de 'E', que traz críticas pertinentes a insuficiência de tais subsídios em relação a prevenção e promoção da saúde do município de 'Presidente Prudente' tencionando a questão local enquanto problema:

Porque você vê campanha de prevenção, de não sei o que, mas elas só são intensificadas em período de carnaval, final de ano, então, são sazonais as datas entendeu?! Quando deveria acontecer uma maior informação durante o ano inteiro porque as pessoas não só transam no carnaval, as pessoas não só transam no final de ano entendeu?! elas transam o ano inteiro entendeu?! (Sujeito E).

Toda esta diversidade discursiva problematiza sobre como é acesso à informação dos serviços de saúde e o impacto da eficácia destes tipos de serviços repercutem na camada jovem da população prudentina, uma vez que as demandas partem dos sujeitos sociais que delas fazem uso.

Assim, levanta-se o questionamento sobre a ampla divulgação dos serviços, bem como a forma que essas informações sobre os serviços de saúde são transmitidas aos jovens. Serão elas apropriadas para a linguagem e interpretação que é pertencente à juventude? Estas estão presentes no meio social onde estes jovens habitam, estudam ou residem? São questões como estas que nos motivam ir a fundo ao contexto geográfico pertencente a estes jovens.

A partir do que se foi exposto podemos interpretar as relações estabelecidas sobre o campo 'Espaços: saúde e doença' de forma que assim, se constitui uma das partes relacionais do contexto DOl:http://dx.doi.org/DOI 10.14393/Hygeia153146917 Hygeia 15 (31): 82 - 94, Março/2019 página 90 
geográfico destes jovens, que, por sinal, deve ser lido como um todo, partindo de uma visão holística. As experiências relacionadas à saúde e doença, envolvem uma vasta gama de informações sobre a vida dos entrevistados, de maneira, que se é possível permear e entender os acontecimentos advindos de tais fenômenos, do viver, adoecer e morrer.

\section{CONCLUSÕES}

Dado a expressividade e a pluralidade encontrada nas análises, entendemos que o contexto geográfico dos jovens não é a soma das partes ou mesmo das classes de análise, mas sim, a relação que se estabelece entre elas, que partem da compreensão dos sujeitos enquanto foco central da pesquisa. É neste sentido que foi de suma importância refletir sobre o conjunto de jovens que foram analisados, uma vez que se evidenciaram problemáticas similares que perpassam a vida de diferentes pessoas, o que nos faz refletir sobre as questões atinentes ao acesso, a interação entre espaços públicos e privados, aos serviços de saúde e a produção e consumo da cidade.

Assim, entendemos que as escalas pertencentes ao espaço urbano são construídas, vividas, sentidas e ressignificadas por estes jovens a partir das experiências que estes têm com o HIV/AIDS, uma vez que tais relações constituem seus contextos geográficos. Partindo da realidade colocada pelos sujeitos, conseguimos visualizar o quão é difícil ser jovem e lidar com as múltiplas interseccionalidades (ROSSI, 2011, BUTLER, 2018). Interseccionalidades estas, que os atravessam enquanto corpos sociais que produzem, vivenciam e consomem o espaço urbano. Esta leitura integrada foi tomada como base na compreensão do contexto geográfico dos jovens, sendo que tais manifestações partem dos corpos e se reverberam nestes, no que tange aos fenômenos sociais, tendo assim, o HIV/AIDS enquanto marco em suas vidas (PEDROSO; GUIMARÃES, 2017).

Foi possível também identificar os impactos causados pelo diagnóstico do HIV/AIDS na vida dos jovens, assim como as dificuldades e ressignificações espaciais decorrentes deste processo de transformação. Também emergiu fatores atinentes a saúde destes jovens, que vão desde problemas referentes à adesão do tratamento, manutenção e qualidade de vida até a cogitação de suicídio, o que expressa elevado grau de complexidade. Desta forma, realizamos uma imersão no mundo destes sujeitos que nos fez compreender o tempo e elementos de apoio (familiares, ONGs, serviços de saúde) enquanto pilares imprescindíveis para a saúde e vida destes sujeitos.

Assim sendo, salientamos os apontamentos feitos pelos entrevistados em relação às políticas públicas de saúde e aos serviços de saúde, relacionados aos espaços que são responsáveis por tal desempenho, de modo, que pudemos compreender a necessidade de se repensar as políticas e estratégias de prevenção e atendimento a essa camada da sociedade em Presidente Prudente. Enfim, reforçamos aqui que cabe a Geografia da Saúde o compromisso de repensar a organização dos serviços e atendimentos frente aquilo que os sujeitos sociais demandam a partir de suas vozes.

\section{AGRADECIMENTOS}

Agradecemos em primeira instância aos entrevistados que se dispuseram em compartilhar suas histórias de vida conosco, somente assim foi possível a materialização deste trabalho. Em especial deixamos nossos sentimentos de saudades e agradecimentos eternos ao 'Sujeito T' (em memória) por partilhar sua vida e seus sonhos que por infelicidade foram interrompidos. Também agradecemos a Fundação de Amparo à Pesquisa do Estado de São Paulo (FAPESP) pelo apoio e fomento desta pesquisa (processo 2014/20724-6).

\section{REFERÊNCIAS BIBLIOGRÁFICAS}

ALMEIDA FILHO, N. O que é saúde? Rio de Janeiro: Editora Fiocruz, 2011, 160 p. https://doi.org/10.7476/9788575413432

ALVES, M. M. M. Distribuição espaço-temporal da Aids no estado de Rondônia, 1994 - 2008.

2010. 78 f. Dissertação (Mestrado em Mobilidade Profissional em Saúde Pública) - Fundação Oswaldo Cruz, FIOÇRUZ.

BARCELLOS, C; BASTOS, F. I. Redes sociais e difusão da AIDS no Brasil. Boletín de la Oficina Sanitaria Panamericana, v.121, n.1, p.11-24, 1996. 
BASTOS, F. I. AIDS na terceira década. Rio de Janeiro: Editora Fiocruz, 2006, 103 p. https://doi.org/10.7476/9788575413012

Saúde em questão. São Paulo: Claro Enigma; Rio de Janeiro: Editora Fiocruz, 2011, 111 p.

BRASIL. Boletim epidemiológico HIV AIDS. Brasília-DF: Ministério da Saúde, Ano III, no 1.

Departamento de DST, Aids e Hepatites Virais, 2014.

. Boletim epidemiológico HIV AIDS. Brasília-DF: Ministério da Saúde, n. 53, v. 49.

Departamento de DST, Aids e Hepatites Virais, 2018.

BUENO, N. H. As doenças infectocontagiosas em cidades de médio porte: uma abordagem qualitativa da AIDS em Piracicaba/SP. 2010. 161 f. Dissertação (Mestrado em Geografia) - Instituto de Geociências e Ciências Exatas, Universidade Estadual Paulista.

BUTLER, J. Corpos em aliança e a política das ruas: notas para uma teoria performativa de assembleia (Trad. Fernanda Siqueira Miguens), $1^{\circ}$ ed. Rio de Janeiro: Civilização Brasileira, 2018, $266 \mathrm{p}$.

CAGUILHEM, G. O normal e o patológico. Trad. Maria Thereza Redig de Carvalho Barrocas e Luiz Octávio Ferreira Barreto Leite. 3. ed. Ver. Aumentada. Rio de Janeiro: Forense Universitária, 1990, $307 \mathrm{p}$.

CASTRO, I. E. O problema da escala. In: CASTRO, I. E; GOMES, P. C. C; CORRÊA, R. L. Geografia: conceitos e temas. $10^{\circ}$ ed. Rio de Janeiro - RJ: Bertrand Brasil, 2007, p. 117-140.

CERTEAU, M. A invenção do cotidiano: 1. Artes de fazer. Petrópolis: Vozes, 2008, 351 p.

CORVINO, J. M. Na companhia do vírus: concepções e vivências de adolescentes portadores do HIV/AIDS. 2012. 75 f. Dissertação (Mestrado para obtenção do título de mestre em Saúde Coletiva) - Universidade Estadual Paulista, Faculdade de Medicina de Botucatu.

COSTA-COUTO, M. H. A vulnerabilidade da vida com HIV/AIDS. 2007. 211 f. Tese (Doutorado) Universidade do Estado do Rio de Janeiro, Instituto de Medicina Social.

CZERESNIA, D. O conceito de saúde e a diferença entre prevenção e promoção. In: CZERESNIA, D; FREITAS, C. M. (Org.). Promoção da Saúde: reflexões, conceitos, tendências. Rio de Janeiro: FIOCRUZ, 2003, p. 39-53.

CZERESNIA, D; MACIEL, E. M. G.S; OVIEDO, R. A. M. Os sentidos da saúde e doença. Rio de Janeiro: Editora Fiocruz, 2013, 119 p. https://doi.org/10.7476/9788575415269

GUIMARÃES, R. B. Regionalização da saúde no Brasil: da escala do corpo à escala da nação. São Paulo, Universidade de São Paulo, Faculdade de Saúde Pública, 2008. (Tese de Livre Docência).

LANGDON, E. J; MALUF, S; TORNQUIST, C. S. Ética e política na pesquisa: os métodos qualitativos e seus resultados. In: GUERRIERO, I. C. Z; SCHMIDT, M. L. S; ZICKER (Org.) Ética nas pesquisas em ciências humanas e sociais na saúde. São Paulo - SP: Hucitec, 2008, p. 128-147.

LIMA, A. A. A; PEDRO, E. N. R. Crescendo com HIV/AIDS: estudo com adolescentes portadoras de HIV/AIDS e suas cuidadoras-familiares. Rev. Latino-Americana de Enfermagem, v. 16, n. 3, p. 1-8, 2008. https://doi.org/10.1590/S0104-11692008000300003

MAINGUENEAU, D. Novas tendências em análise do discurso. 3. ed. Campinas - SP: Pontes: Editora da Universidade Estadual de Campinas, 1997.

MANZINI, E. J. A entrevista na pesquisa social. Rev. Didática, São Paulo, v. 26, n. 27, p. 149-158, 1991.

Considerações sobre a transcrição de entrevistas. In: MARQUEZINI, M. C.; MARCONI, M. A.; LAKATOS, E. M (Org.). Técnicas de Pesquisa: planejamento e execução de pesquisas. Amostragens e técnicas de pesquisa. Elaboração, análise e interpretação de dados. 7.ed. São Paulo: Atlas, 2010.

. Entrevista semi-estruturada: análise de objetivos e de roteiros. In: SEMINÁRIO INTERNACIONAL SOBRE PESQUISA E ESTUDOS QUALITATIVOS, 2004, Bauru. Anais. Bauru: USC, 2004. v. 1. p. 1-10. 
MARCHETTI, M. C. O perfil da população e a espacialização dos casos registrados de AIDS em Londrina: uma contribuição para a Geografia da Saúde. 2011. 169 f. Dissertação (Mestrado em Geografia) - Centro de Ciências Exatas, Universidade Estadual de Londrina.

MARSTON, S. A. The social construction of scale. Progress in Human Geography. v. 24, n. 2, p. 219-242, 2000. https://doi.org/10.1191/030913200674086272

MONTEIRO, S. Qual prevenção? Aids, sexualidade e gênero em uma favela carioca. Rio de Janeiro: Editora Fiocruz, 2002, 148 p. https://doi.org/10.7476/9788575415214

NUNES, S. O. V; et al. Determinação dos diagnósticos de depressão, tentativa de suicídio, gravidez, vírus da imunodeficiência humana (HIV) e doenças sexualmente transmissíveis (DST) em adolescentes e adultos jovens. Rev. Semina: Ciências Biológicas e da Saúde, Londrina, v. 26, n. 2, p.109 - 118, 2005.

OLIVEIRA, D. R. A dinâmica da distribuição espacial da infecção por HIV e da mortalidade por AIDS no município de São Paulo de 1996 a 2007. 2011. 100 f. Dissertação (Mestrado em Geografia) - Faculdade de Filosofia, Letras e Ciências Humanas, Universidade de São Paulo.

OLIVEIRA, S. F. As vozes presentes no texto acadêmico e a explicitação da autoria. Pedagogia em Ação, Belo Horizonte, v. 6, n. 1, p. 03-21, 2014.

ORNAT, M. J. Território da prostituição e instituição do ser travesti em Ponta Grossa - PR. 2008. 160 f. Dissertação (Mestrado no Programa de Pós-Graduação em Geografia, Mestrado em Gestão do Território, Setor de Ciências Exatas e Naturais) Universidade Estadual de Ponta Grossa, Ponta Grossa, 2008.

PÁRAMO, M. A. Análisis cualitativo de discursos grupales asistido por programa de software textstat: valoración de suutilidad em la exploración y relación de significados. Rev. LIBERABIT. Lima (Perú), v. 16, n. 2, p. 141-151, 2010.

PAULA, F. M. A; PIRES, L. M. Os jovens e a cidade: práticas espaciais, redes de sociabilidade e constituição de territorialidades. Caderno Prudentino de Geografia. Presidente Prudente, volume especial, n. 35, p. 87-106, 2013.

PEDROSO, M. F. Contextos geográficos da AIDS e os espaços vividos por jovens com HIV em Presidente Prudente - SP. 2017. 243 f. Monografia (Graduação em Geografia) - Faculdade de Ciências e Tecnologia, Universidade Estadual Paulista - UNESP, Presidente Prudente.

PEDROSO, M. F. Metodología, Salud y Geografía: el poder de las palabras para la comprensíon del VIH/SIDA en jóvenes. In: II Encuentro Argentino-Brasileiro: Debates acerca del doctorado em Geografia, 2016, San Juan -Argentina, p. 1-5, 2016.

PEDROSO, M. F; GUIMARÃES, R. B. A análise da subjetividade em Geografia da Saúde: abordagem qualitativa de soropositivos em HIV em Presidente Prudente - SP. Rev. Geografia em Atos (Online), v. 2, p. 1-9, 2015.

. Marcas do HIV/AIDS em Corpos Jovens: Rupturas e Ressignificações no Espaço Urbano.

Rev. Latino Americana de Geografia e Gênero, v. 8, n. 2, p. 23-50, 2017.

https://doi.org/10.5212/Rlagg.v.8.i2.0002

PESSÔA, V. L. S; RAMIRES, J. C. L. Amostragem em pesquisa qualitativa: subsídios para a pesquisa geográfica. In: MARAFON, G, J; RAMIRES, J, C. L; RIBEIRO, M, A; PESSÔA, V, L, S. Pesquisa qualitativa em Geografia. Rio de Janeiro - RJ: EdUERJ, 2013, p. 117-134.

PRADO, R. R. Análise espaço-temporal dos casos de aids no estado de São Paulo - 1990 a 2004. 2008. 106 f. Tese (Doutorado em Ciências - Medicina Preventiva) - Faculdade de Medicina, Universidade de São Paulo.

ROJAS, L. I. Geografía y salud. Entre Historias, Realidades y utopias. Caderno Prudentino de Geografia. Associação dos Geógrafos Brasileiros. v.1 n. 1, p. 9-28, 2003.

ROSSI, R. Masculinidades e interseccionalidade na vivência de territórios instituídos por adolescentes em conflito com a lei. In: SILVA, J. M; ORNAT, M. J; CHIMIN JUNIOR, A. B. Espaço, gênero \& masculinidades plurais. Ponta Grossa: Todapalavra, 2011. p. 125-191. 
SCHAURICH, D; COELHO, D. F; MOTTA, M. G. C. A Cronicidade no Processo Saúde-Doença: repensando a epidemia da AIDS após os anti-retrovirais. Rev. Enfermagem (UERJ), Rio de Janeiro, v. 14, n.3, p. 455-462, 2006.

SILVA, L. C. F. HIV/AIDS: Padrões epidêmicos e espaciais na cidade de Manaus, Amazonas, 1986 a 2000. 2003. 175 f. Dissertação (Mestrado em Ciências na área de Saúde Pública) - Escola Nacional de Saúde Pública Sérgio Arouca, ENSP.

SOUZA, T. R. C. Impacto psicossocial da AIDS: enfrentando as perdas... ressignificando a vida. 2008. 90 f. Tese (Doutorado Centro de Referência e Treinamento DST/Aids), 2008.

STOTZ, E. N; ARAUJO, J. W. G. Promoção da saúde e cultura política: a reconstrução do consenso. Rev. Saúde e sociedade, v. 13, n. 2, p. 5-19, 2004. https://doi.org/10.1590/S010412902004000200002

STRAUSS, A; CORBIN J. Pesquisa qualitativa: técnicas e procedimentos para o desenvolvimento de teoria fundamentada. 2. ed. Porto Alegre - RS: Artmed, 2008.

VERDI, M; CAPONI, S. Reflexões sobre a promoção da saúde numa perspectiva bioética. Texto Contexto Enferm, v. 14, n. 1, p. 82-88, 2005. https://doi.org/10.1590/S0104-07072005000100011

ZUSMAN, P. La tradición del trabajo de campo em Geografía. Geograficando, v. 7, n. 7, p. 15-32, 2011. 